\title{
On the Dynamics of Spatial Updating
}

\author{
Jean Blouin ${ }^{1 *}$, Jean-Philippe Pialasse ${ }^{2}$, Laurence Mouchnino ${ }^{1,3}$ and Martin Simoneau ${ }^{2,4}$ \\ 'Laboratoire de Neurosciences Cognitives, CNRS, Aix-Marseille Université, Marseille, France, ${ }^{2}$ Département \\ de Kinésiologie, Faculté de Médecine, Université Laval, Québec, QC, Canada, ${ }^{3}$ Institut Universitaire de France, Paris, \\ France, ${ }^{4}$ Centre Interdisciplinaire de Recherche en Réadaptation et Intégration Sociale du CIUSSS de la Capitale-Nationale, \\ Québec, QC, Canada
}

\section{OPEN ACCESS}

Edited by:

Notger G. Müller,

University of Potsdam, Germany

Reviewed by:

Andrea Canessa,

University of Genoa, Italy

Georg Jahn,

Chemnitz University of Technology,

Germany

*Correspondence:

Jean Blouin

jean.blouin@univ-amu.fr

Specialty section: This article was submitted to

Perception Science,

a section of the journal

Frontiers in Neuroscience

Received: 20 September 2021

Accepted: 24 January 2022

Published: 17 February 2022

Citation:

Blouin J, Pialasse J-P, Mouchnino L and Simoneau M (2022) On the Dynamics of Spatial Updating. Front. Neurosci. 16:780027. doi: 10.3389/fnins.2022.780027
Most of our knowledge on the human neural bases of spatial updating comes from functional magnetic resonance imaging (fMRl) studies in which recumbent participants moved in virtual environments. As a result, little is known about the dynamic of spatial updating during real body motion. Here, we exploited the high temporal resolution of electroencephalography (EEG) to investigate the dynamics of cortical activation in a spatial updating task where participants had to remember their initial orientation while they were passively rotated about their vertical axis in the dark. After the rotations, the participants pointed toward their initial orientation. We contrasted the EEG signals with those recorded in a control condition in which participants had no cognitive task to perform during body rotations. We found that the amplitude of the $\mathrm{P}_{1} \mathrm{~N}_{1}$ complex of the rotation-evoked potential (RotEPs) (recorded over the vertex) was significantly greater in the Updating task. The analyses of the cortical current in the source space revealed that the main significant task-related cortical activities started during the $\mathrm{N}_{1} \mathrm{P}_{2}$ interval (136$303 \mathrm{~ms}$ after rotation onset). They were essentially localized in the temporal and frontal (supplementary motor complex, dorsolateral prefrontal cortex, anterior prefrontal cortex) regions. During this time-window, the right superior posterior parietal cortex (PPC) also showed significant task-related activities. The increased activation of the PPC became bilateral over the $\mathrm{P}_{2} \mathrm{~N}_{2}$ component (303-470 ms after rotation onset). In this late interval, the cuneus and precuneus started to show significant task-related activities. Together, the present results are consistent with the general scheme that the first task-related cortical activities during spatial updating are related to the encoding of spatial goals and to the storing of spatial information in working memory. These activities would precede those involved in higher order processes also relevant for updating body orientation during rotations linked to the egocentric and visual representations of the environment.

Keywords: space updating, idiothetic, vestibular processing, cortical network, cortical source, EEG, human

\section{INTRODUCTION}

The capacity to keep track of our position in the environment is paramount when moving around. This cognitive skill is generally referred to as spatial navigation. In humans, large advances on the neural bases of spatial navigation were obtained by measuring the cerebral blood flow, with fMRI scanners, of recumbent participants virtually moving in visual environments. Studies employing these techniques have revealed a consistent set of cortical activations during spatial navigation (Ekstrom et al., 2003; Hartley et al., 2003; Wolbers et al., 2008; Nemmi et al., 2013; Sherril et al., 2015; Balaguer et al., 2016; Vass and Epstein, 2017). 
Increased activations were found in areas responding to visual stimuli (striate and extrastriate visual areas), and in regions not strictly involved in visual processing yet having important higherorder functions for spatial navigation. These regions include the PPC, the temporal (TC) and frontal cortices which contribute, in varying degrees, to working memory, space perception and spatial representations.

The dynamics of the neural network underlying spatial navigation uncovered by fMRI studies is largely unknown. This is notably due to the hemodynamic response time (Ghuman and Martin, 2019) which is too slow with respect to the speed of the processes engaged during spatial navigation (e.g., $<1.5 \mathrm{~s}$ for simple spatial updating tasks, Rieser, 1989; Hodgson and Waller, 2006; Boon et al., 2018). One can reasonably expect that the dynamics are conditioned, to some extent, by the functions of the different elements comprising the engaged network. For instance, early and sustained activation could be found in the areas which contribute to maintaining spatial information in short-term working memory [e.g., dorsolateral prefrontal cortex (dlPFC), see Wager and Smith, 2003; Gilbert and Burgess, 2008] and to processing external spatial information, such as goal destination [e.g., anterior PFC (aPFC), see Ekstrom et al., 2003; Ciaramelli, 2008; Spiers, 2008; TC, see Ekstrom et al., 2003; Hartley et al., 2003]. On the other hand, later activations are to be expected in regions involved in higher cognitive processes. This could be the case for the regions that contribute to the building of egocentric and allocentric frames of reference, respectively allowing individuals to either encode the environment relative to themselves (e.g., precuneus, Byrne et al., 2007) or to encode their position relative to the environment [e.g., lateral occipital cortex (LOC), Committeri et al., 2004; Zaehle et al., 2007].

Electroencephalography (EEG), with its excellent temporal resolution and the possibility to increase its spatial resolution using source analyses techniques (Im et al., 2007; Tadel et al., 2011, 2019), appears well adapted to capture the time course of spatial navigation (Schneider et al., 1996; Gutteling et al., 2015; Gale et al., 2016; Gutteling and Medendorp, 2016; Ertl et al., 2017). Moreover, the use of EEG also enables the investigation of brain activity in moving participants, i.e., where vestibular inputs provide the brain with critical body motions information for spatial navigation (Brandt et al., 2005; Kremmyda et al., 2016; Schöberl et al., 2021; see Smith, 2017, for a review).

Gutteling et al. (2015) and Gutteling and Medendorp (2016) recently used EEG to record cortical activities of participants who had to retain the location of a peripheral target during passive whole-body motion in the dark (see Medendorp and Selen, 2017, for a review). Investigating these activities in such spatial updating task can be thought of as a valuable entry point for getting insight into the cortical implementation of spatial navigation. Performed relatively well in darkness (see Klier and Angelaki, 2008; Medendorp, 2011, for reviews), even in extreme cases of somatosensory deafferentation (Blouin et al., 1995), such tasks involve vestibular information processing. Gutteling et al. (2015) and Gutteling and Medendorp (2016) found a large alpha power decrease in electrodes overlaying the PPC during spatial updating. Interestingly, the decreased alpha power was always located in the contralateral hemisphere to the memorized target and switched hemisphere when the unseen target changed visual hemifield during body motion. Reflecting enhanced cortical excitability (Jasper and Penfield, 1949; Pfurtscheller and Lopes da Silva, 1999), the decrease of alpha power observed during the actual body motion provided human electrophysiological evidence that the PPC is involved in spatial updating (Duhamel et al., 1992; Medendorp et al., 2003; Merriam et al., 2003; VentreDominey and Vallee, 2007) and in directing attention to locations or objects in the environment (Corbetta and Shulman, 2002).

Apart from the PPC, no other region of the spatial navigation network revealed by human fMRI investigations (see above) showed task-related neural oscillations in Gutteling et al.'s (2015) and Gutteling and Medendorp (2016) studies. This could be due to the fact that the EEG spectral content was examined in the electrode space (scalp level) rather than in the sources space. By partially de-convolving the EEG data in a physically and anatomically meaningful way, source space analyses may indeed reveal effects that remain undetected at the scalp level with electrode space analyses (Baillet et al., 2001; Salmelin and Baillet, 2009).

The goal of the present study was twofold: to analyze the cortical network involved in spatial updating during actual whole-body motion in the dark, and to obtain insight into the dynamics of this network. We performed source analyses of the EEG activity recorded while human participants were maintaining their initial orientation in memory while being rotated in darkness. The dynamics of the early stage of spatial updating (i.e., before predominance of processes related to the use of the updated spatial representation) was assessed by computing the current amplitude over the cortical surface in three consecutive time windows. These were defined by the negative and positive deflection points of the rotation evoked potential (RotEPs) recorded over the vertex. We predicted that the first task-related activations should be observed in areas involved in the short-term spatial working memory (e.g., dlPFC; Wager and Smith, 2003) and the online spatial updating processes (e.g., PPC; Duhamel et al., 1992; Gutteling et al., 2015; Gutteling and Medendorp, 2016). Later activations should be observed in regions involved in the egocentric encoding of spatial positions (e.g., precuneus, Byrne et al., 2007).

\section{MATERIALS AND METHODS}

The data were collected in a previous study (Blouin et al., 2019). In this study, we specifically investigated the cortical activation associated with the planning of pointing movements whose targets were defined by idiothetic information issued from body rotations in the dark. This activation was assessed from the end of the rotation to the onset of the pointing movements (i.e., movement planning process). In the present study, we investigated the dynamics of cortical activation during the actual body motion (i.e., spatial updating process).

\section{Participants}

Ten healthy right-handed participants (three women, mean age: $26.6 \pm 2.7$ years) participated in the experiment. They all had 
normal or corrected-to-normal vision and did not report any history of neural disorders. The data of one male participant had to be discarded because of technical problems. The experiment was conducted in accordance with the Declaration of Helsinki (except for registration in a database) and was approved by the Laval University Biomedical Ethics Committee. Informed consent was obtained prior to the experiment.

\section{Experimental Set-Up}

The participants were seated in a dark room with their feet resting on a footstool. They were secured to the chair with a four-point belt. The chair could be manually rotated about its vertical axis by the experimenter. The rotations were recorded with an optical encoder at $1 \mathrm{kHz}$. A circular array of LEDs fixed on the floor behind the chair indicated its initial angular position and the three targets rotations (i.e., $20^{\circ}, 30^{\circ}$ and $40^{\circ}$ in the counterclockwise direction). A light emitted by a laser diode fixed on the back of the chair provided the experimenter with visual feedback about the chair orientation along the LEDs array. The use of different rotation amplitudes together with the variability in the actual body rotation (e.g., acceleration, amplitude) for a given rotation target amplitude increased the necessity for the participants to direct their attention on information related to self-rotation to keep track of their initial orientation. Similar set-ups have frequently been used for testing vestibular-related processes (e.g., Blouin et al., 1998, 2010; Hanson and Goebel, 1998; Funabiki and Naito, 2002; Mackrous et al., 2019). Importantly, the choice of manual rotations reduced the possibility of electric noise contamination of the EEG recordings (see Nolan et al., 2009 for a discussion on this issue).

\section{Experimental Tasks Updating}

Before the start of each trial, participants positioned their right hand on their ipsilateral knee and gazed at a chair-fixed LED positioned $\sim 1 \mathrm{~m}$ in front of them. They were instructed to keep fixating this LED during the whole duration of the trials. The participants received the preparation signal "ready" $2-3 \mathrm{~s}$ before either the $20^{\circ}, 30^{\circ}$, or $40^{\circ}$ floor LED lit up behind the chair to indicate, to the experimenter, the amplitude of the next rotation. Some $100 \mathrm{~ms}$ after the end of the rotation, a beep indicated to the participants to produce a rapid lateral arm movement to point toward their pre-rotation, initial, orientation. The signal from the chair optical encoder was used to detect online the end of the rotation which was defined as angular velocity smaller than $2.5^{\circ} / \mathrm{s}$. The buzzer emitting the beep was located directly above the participants, along their longitudinal axis. This prevented the sound from providing spatial information (e.g., initial orientation). The participants were returned to the starting position after their pointing response and the next trial started following a minimum resting time of $15 \mathrm{~s}$. Results related to the motor performance have been published separately (Blouin et al., 2019). Briefly, the burst of the arm muscular activities triggering the pointing movements occurred $\sim 400 \mathrm{~ms}$ after the imperative signal (beep) and the amplitude of the movements was scaled according to the amplitude of the body rotations. These behavioral results prove that the participants attempted to remember their initial orientation while they were passively rotated. They also indicate that spatial updating was fast and attuned to the actual body rotation in space.

\section{Control}

We performed a second experimental block of trials like those performed in the Updating task, but with the only distinction that the participants did not produce arm movement when hearing the beep after the rotation offset. For these trials, the instruction was simply to keep ocular fixation on the chair-fixed LED during the rotations. This block of trials was used to normalize EEG activities recorded in the Updating task. As the dynamics of the body rotations were similar in both the Updating and Control tasks, as it will be demonstrated below, this normalization (also detailed below) allowed EEG activities that are not strictly related to spatial updating to be to canceled out (see Gutteling et al., 2015). These activities might result for instance from eye movements, and from somatosensory (see Ertl and Boegle, 2019) stimulation during body rotations. Note, however, that important activities for spatial updating could also be present in both the Updating and Control tasks. This could be the case for activities related to vestibular stimulation and to activities where attention is directed toward self-motion information.

Participants were submitted to 25 rotations for each angular target for a total of 75 trials in each task (i.e., Updating and Control). The order of rotation amplitude was pseudorandomly selected and the presentation order of the tasks was counterbalanced across participants.

On average (Control and Updating tasks), the rotation amplitudes were $19.81 \pm 0.83^{\circ}, 29.67 \pm 0.96^{\circ}$, and $40.53 \pm 0.94^{\circ}$ for the $20^{\circ}, 30^{\circ}$, and $40^{\circ}$ rotation tasks, respectively (see Figure 1). To verify if participants experienced similar idiothetic

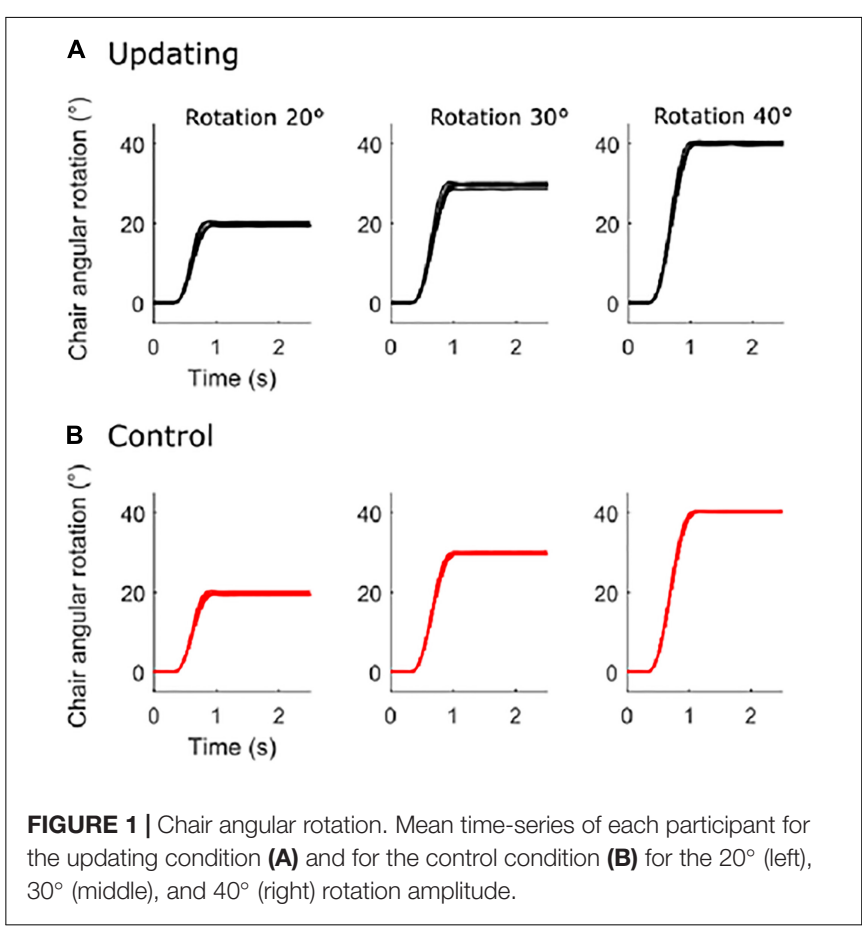


information between the Updating and Control tasks, we compared chair angular acceleration between both tasks. To make this test, we first normalized the time-series of angular acceleration from start (0\%) to end (100\%); using an angular velocity threshold of $2.5^{\circ} \mathrm{s}$ to identify beginning and ending of rotation. Then, for each chair rotation amplitude (i.e., $20^{\circ}, 30^{\circ}, 40^{\circ}$ ), we performed a two-tailed paired $t$-test using statistical parametric mapping (SPM) analyses. SPM uses random field theory to adjust for multiple comparisons. It enables comparison of continuous variables at time points other than discrete local optima (Pataky et al., 2013). This statistical approach is suited to analyzing time-series where each sample is dependent on previous data points, as for acceleration data. For each rotation amplitude, results of the statistical tests revealed that the time-series acceleration did not significantly differ between the Updating and Control tasks (all $P$ s $<0.05$; Figure 2). These results suggest that if the dynamics of cortical activities differed between the Updating and Control tasks, this difference more likely would result from a difference between the cortical processes engaged within the tasks than from different idiothetic information.

\section{Electroencephalographic Analyses}

Electroencephalographic (EEG) activity was recorded using a Geodesic 64-channel EEG sensor net $(1000 \mathrm{~Hz}$, Electrical Geodesics Inc., Eugene, United States). This electrode density is considered appropriate for electrophysiological source imaging (Seeck et al., 2017). Data pre-processing was performed using BrainVision Analyzer 2 (Brain Products, Gilching, Germany). The recordings were first referenced to the averaged activity of the 64 scalp electrodes. Then, data recorded by all electrodes were synchronized with respect to the onset of the rotation (i.e., when chair angular velocity $>2.5^{\circ} / \mathrm{s}$ ), with the average amplitude of the 200-ms pre-rotation epoch serving as baseline. The signals were band-passed filtered $(0.5-45 \mathrm{~Hz})$ and independent component analyses (ICA) were used to subtract ocular artifacts (e.g., blinks, saccades) from the EEG recordings. The recordings were visually inspected and epochs still presenting artifacts were rejected. The data were separately averaged for each participant, task, target body angular rotation amplitude (i.e., $20^{\circ}, 30^{\circ}, 40^{\circ}$ ) and electrode. These averages were used to estimate the sources of the cortical activities.

The cortical sources were reconstructed using Brainstorm software (Tadel et al., 2011, freely available at http://neuroimage.usc.edu/brainstorm). We employed the minimum-norm technique to resolve the inverse problem with unconstrained dipole orientations. The forward models were computed using a boundary element method (symmetric BEM, Gramfort et al., 2010) on the anatomical MRI Colin 27 brain template, a predominant volume conductor model from the Montreal Neurological Institute. We used a BEM model with three realistic layers (scalp, inner skull, and outer skull) which
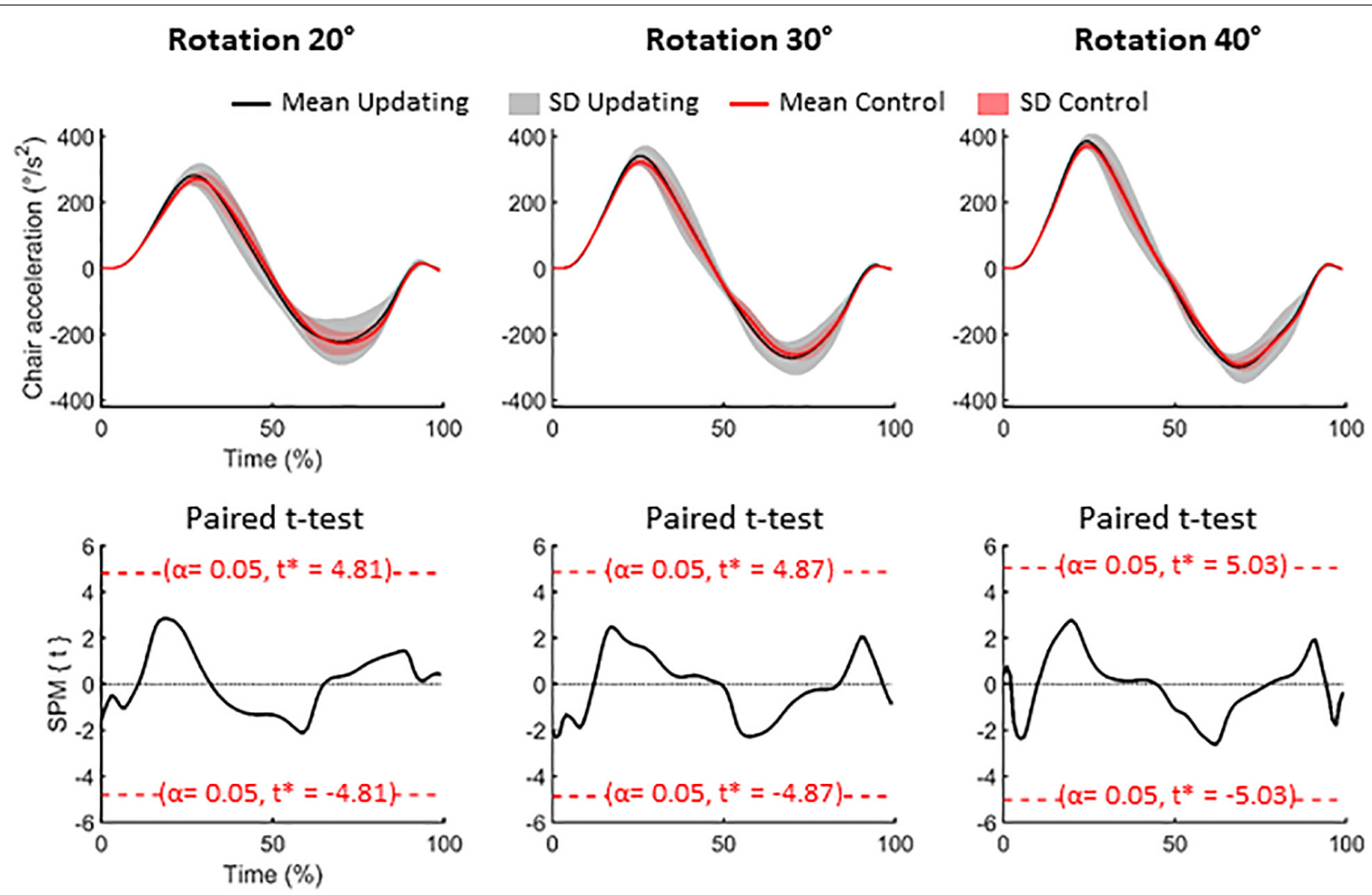

FIGURE 2 | Data related to the chair rotations. Upper panels: mean (solid lines) and standard deviation (SD, areas) of the acceleration of the chair for the $20^{\circ}$ (left), $30^{\circ}$ (middle) and $40^{\circ}$ (right) rotation amplitude. Black time-series depict the group-mean for the Updating condition while the red time-series illustrate the group-mean for the Control condition. Lower panels: results of the paired $t$-test for each rotational amplitude. SPM\{t\} represents the temporal trajectory of the $t$ statistic (black lines) and the critical threshold (red lines, $\alpha=0.05)$. $T$-score for each comparison is illustrated in each panel. 
provides more accurate solution than a simple three concentric spheres model (Sohrabpour et al., 2015). To enhance the spatial resolution of the brain template, we used a high number of vertices (i.e., 306,716 vertices). Such source reconstruction of EEG data has proved to be suited for investigating the activity of outer and inner cortical surfaces (Ponz et al., 2014; Chand and Dhamala, 2017).

Consistent with previous studies (Schneider et al., 1996; Gale et al., 2016; Ertl et al., 2017), RotEPs were found over a large set of electrodes, but were largest over the $\mathrm{Cz}$ electrode (i.e., vertex). As shown in Figure 3 (left column: averaged RotEP; right column: individual RotEP), the RotEPs were composed of successive inflection points which we refer to as $\mathrm{P}_{1}$ (overall mean $47 \pm 12 \mathrm{~ms}), \mathrm{N}_{1}(136 \pm 12 \mathrm{~ms}), \mathrm{P}_{2}(303 \pm 35 \mathrm{~ms})$, and $\mathrm{N}_{2}$ (470 $\left.\pm 55 \mathrm{~ms}\right)$. These points served as temporal landmarks for analyzing the dynamic of the cortical activities in the source space.

For each participant, rotation amplitude and task, we measured the latency of each RotEP's inflection point and then averaged the current computed in the source space over three successive time windows: $\mathrm{P}_{1} \mathrm{~N}_{1}, \mathrm{~N}_{1} \mathrm{P}_{2}$, and $\mathrm{P}_{2} \mathrm{~N}_{2}$. Following this step, we collapsed (by averaging) the maps obtained for each amplitude of rotations to obtain a single map of current amplitude per participant and task. Following trial rejections, the averaged current maps were built using an average number of trials of 61.33 and 63.22 for the Updating and Control conditions,
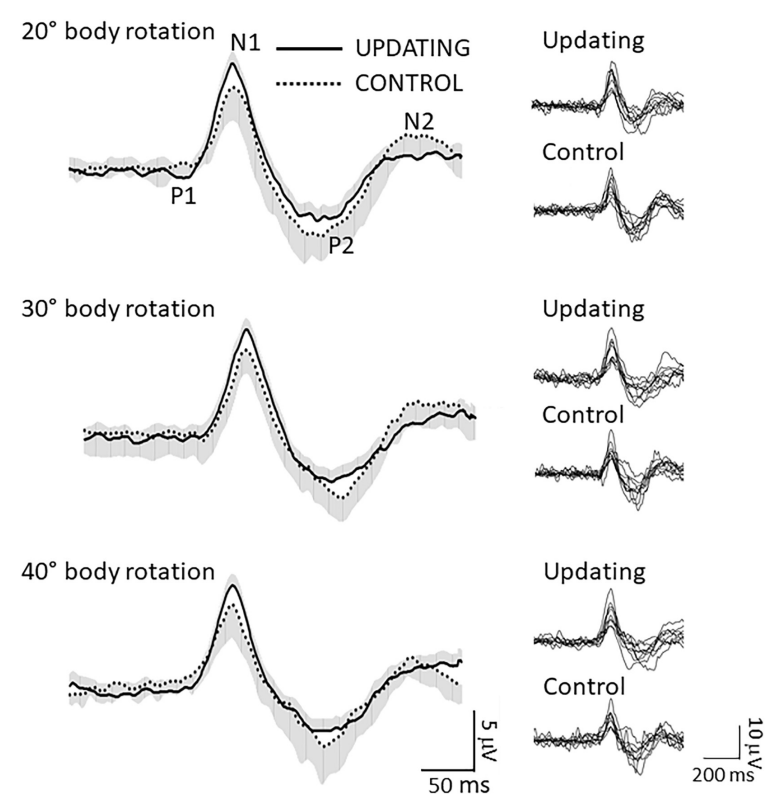

FIGURE 3 | Data related to the rotation evoked potentials (RotEP). (Left column) Grand average RotEP traces at electrode $\mathrm{Cz}$ (i.e., vertex) in the Updating and Control conditions for the $20^{\circ}, 30^{\circ}$, and $40^{\circ}$ body rotations. The shaded areas represent the standard deviation of the means (positive and negative, for the Updating and Control conditions, respectively). The averages were obtained after synchronizing the traces with respect to $N_{1}$. Overall mean peak latencies: $P_{1}: 47 \pm 12 \mathrm{~ms} ; N_{1}: 136 \pm 12 \mathrm{~ms} ; P_{2}: 303 \pm 35 ; N_{2}$ : $470 \pm 55$ ms. (Right column) Individual RotEP of all participants in the Updating and Control conditions, for the $20^{\circ}, 30^{\circ}$, and $40^{\circ}$ body rotations. respectively. It should be noted that this method for estimating EEG sources is not impacted by potential effects of rotation amplitudes, task or inter-individual differences on RotEPs peak latencies. Computed in the source space, current amplitude is considered to reflect brain activation (Tadel et al., 2011, 2019). The last RotEP peak considered in the Updating task (i.e., $\mathrm{N}_{2}$ ) occurred on average 171,269 , and $326 \mathrm{~ms}$ before the end of the $20^{\circ}, 30^{\circ}$ and $40^{\circ}$ rotations. Thus, different cortical activations between the Updating and Control tasks would likely be more related to spatial updating than to the preparation of the arm motor commands in the Updating task.

To highlight those cortical regions specifically involved in spatial updating, we computed statistical maps by contrasting the current maps (i.e., each vertice) obtained in the Updating and Control tasks using $t$-tests (significance threshold $p<0.05$, uncorrected). These analyses were performed separately for each time windows (i.e., $\mathrm{P}_{1} \mathrm{~N}_{1}$ : short latency, $\mathrm{N}_{1} \mathrm{P}_{2}$ : midlatency and $\mathrm{P}_{1} \mathrm{~N}_{2}$ : long latency) to gain insight into the spatiotemporal dynamics of the cortical activities during spatial updating. Sources were identified according to Brodmann's areas after converting MNI to Talairach coordinates with the Nonlinear Yale MNI to Talairach Conversion Algorithm (Lacadie et al., 2008a). The Brodmann's areas definition was based on Lacadie et al. (2008b).

The amplitude of the cortical potentials increases when they are evoked by task-relevant somatosensory (CybulskaKlosowicz et al., 2011; Saradjian et al., 2013) or visual (Lebar et al., 2015) events. In the present study, extracting the RotEPs out of the EEG recordings allowed us to determine if this effect generalized to cortical responses evoked by idiothetic information relevant for spatial updating. To this end, we compared the amplitude of the $\mathrm{P}_{1} \mathrm{~N}_{1}, \mathrm{~N}_{1} \mathrm{P}_{2}$, and $\mathrm{P}_{1} \mathrm{~N}_{2}$ components between the Updating and Control tasks. We also compared between these tasks, the latency of the RotEPs, which was defined as the time elapsed between the onset of the body rotation and $\mathrm{P}_{1}$. Variables related to the RotEP were submitted to separate 2 (Task: Updating, Control) by 3 (Amplitude: $20^{\circ}$, $30^{\circ}, 40^{\circ}$ ) repeated-measures ANOVAs (significance threshold $p<0.05$ ). Prior tests (Kolmogorov-Smirnov) confirmed the normality of all data.

\section{RESULTS}

\section{Rotation-Evoked Potentials}

The ANOVA revealed a significant effect of Task on $\mathrm{P}_{1} \mathrm{~N}_{1}$ component amplitude (Figure 4). The amplitude of this first Rotation-Evoked Potentials (RotEP) component was greater in the Updating than in the Control task $(8.83 \pm 3.18 \mathrm{mV}$ vs. $\left.7.76 \pm 3.14 \mathrm{mV}, F_{1,8}=5.66, p=0.04 ; \eta_{\mathrm{p}}^{2}=0.44\right)$. The analyses did not reveal significant effect of rotation Amplitude $(p=0.38)$ or significant interaction of Task $\times$ rotation Amplitude $(p=0.09)$. The experimental tasks did not have significant effect on the other RotEP components (i.e., $\mathrm{N}_{1} \mathrm{P}_{2}: p=0.56 ; \mathrm{P}_{2} \mathrm{~N}_{2}: p=0.09$ ).

The latency of the RotEPs (i.e., $\mathrm{P}_{1}$, mean $47 \pm 12 \mathrm{~ms}$ ) was not significantly different between the Updating and Control tasks $(p=0.64)$ or between the different rotation amplitudes 

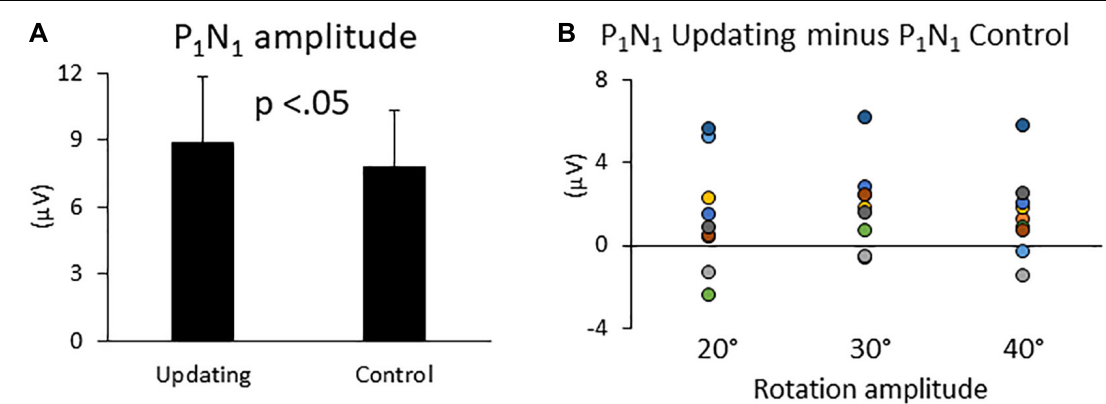

FIGURE 4 | (A) Mean $\mathrm{P}_{1} \mathrm{~N}_{1}$ amplitudes in the Updating and Control conditions. Error bars represent the error standard of the means. (B) Difference between the $\mathrm{P}_{1} \mathrm{~N}_{1}$ amplitudes computed in the Updating and Control conditions. Dots of the same color represent data from the same participant.

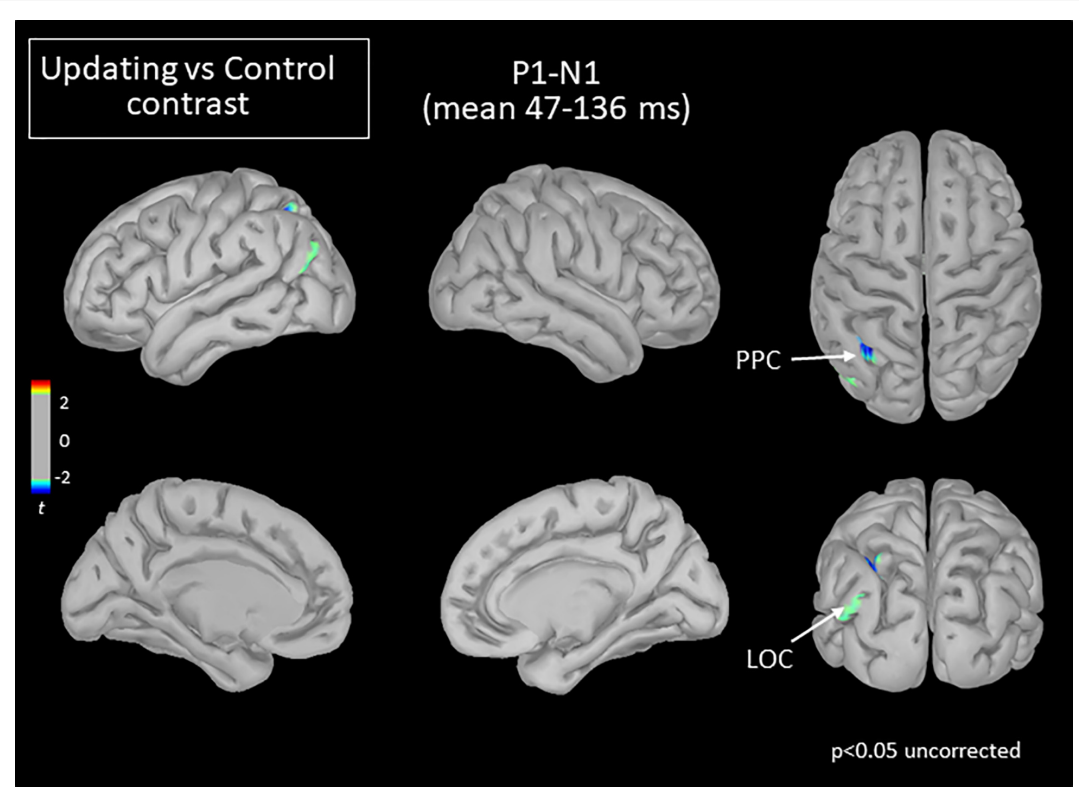

FIGURE 5 | Statistical map (cortex only, $p<0.05$ uncorrected) for the Updating vs. Control contrast computed during the $\mathrm{P}_{1} \mathrm{~N}_{1}$ component of the RotEP. The $t$-test analysis did not reveal significant effect when correcting for multiple comparisons (FDR correction). PPC, posterior parietal cortex; LOC, lateral occipital cortex.

$(p=0.60)$. The interaction Task $\times$ rotation Amplitude was also not significant $(p=0.19)$.

\section{Dynamics of Cortical Source Activity During Spatial Updating}

The statistical maps computed over the 3 RotEP components (i.e., $\mathrm{P}_{1} \mathrm{~N}_{1}, \mathrm{~N}_{1} \mathrm{P}_{2}$, and $\mathrm{P}_{2} \mathrm{~N}_{2}$ ) are shown in Figures 5-7. In these figures, warm color shadings indicate that the current computed in the Updating task was significantly greater than in the Control task. Cold color shadings indicate the opposite pattern. The MNI coordinates of maximal significant current difference between the Updating and Control tasks and their corresponding Brodmann areas are presented in Tables 1-3 for $\mathrm{P}_{1} \mathrm{~N}_{1}, \mathrm{~N}_{1} \mathrm{P}_{2}$, and $\mathrm{P}_{2} \mathrm{~N}_{2}$, respectively.

The mean current measured over the $\mathrm{P}_{1} \mathrm{~N}_{1}$ interval, that is, between 47 and $136 \mathrm{~ms}$ after rotation onset, was strikingly alike between the Updating and Control tasks. The statistical map indicated that the cortical activity did not significantly differ between both tasks except for small areas of the left PPC and left LOC (see Figure 5). In these areas, the activity was smaller in the Updating than in the Control task.

Extensive differences in cortical current between both tasks emerged, however, in the second RotEP component $\left(\mathrm{N}_{1} \mathrm{P}_{2}\right.$, between 130 and $303 \mathrm{~ms}$ after rotation onset). Overall, the cortical activity increased when participants tracked their initial position during the body rotations (see Figure 6). Significant task-related activities were mainly source-localized in the frontal and temporal cortices. Specifically, the supplementary motor complex (SMC), the dorsolateral prefrontal cortices (dlPFC), and the right anterior prefrontal cortex all showed greater activation in the Updating than in the Control tasks. Significantly greater current in the Updating task was also found in the right TC and in both medial TC, and in a small area of the right PPC. Only sparse regions of the LOC showed greater activation in the Control task than in the Updating task. 


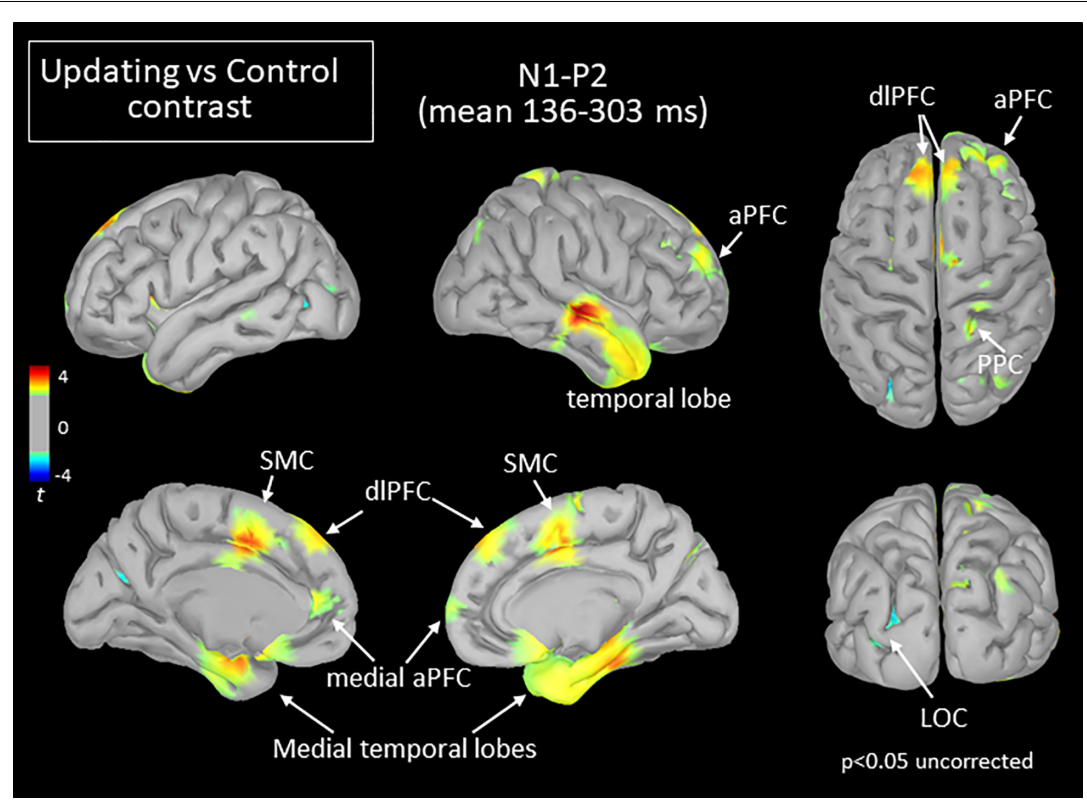

FIGURE 6 | Statistical map (cortex only, $p<0.05$ uncorrected) for the Updating vs. Control contrast computed during the $\mathrm{N}_{1} \mathrm{P}_{2}$ component of the RotEP. The $t$-test analysis did not reveal significant effect when correcting for multiple comparisons (FDR correction). aPFC, anterior prefrontal cortex; dIPFC, dorsolateral prefrontal cortex; LOC, lateral occipital cortex; PFC, prefrontal cortex; PPC, posterior parietal cortex; SMC, supplementary motor complex.

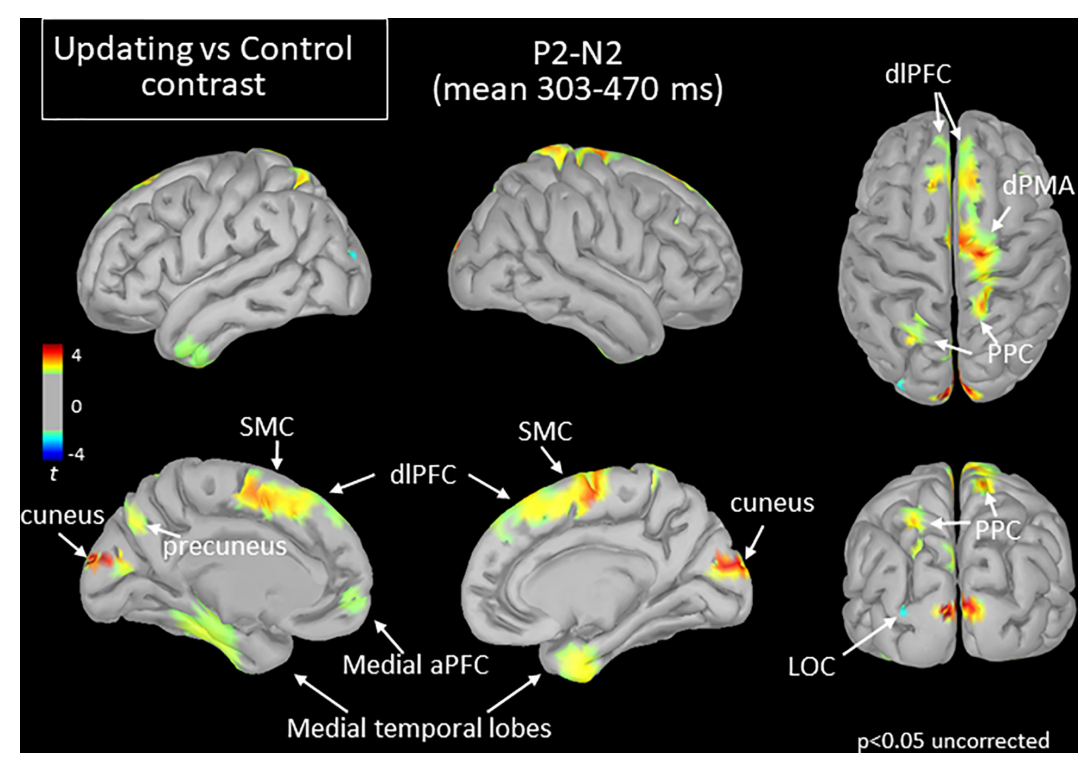

FIGURE 7 | Statistical map (cortex only, $p<0.05$ uncorrected) for the Updating vs. Control contrast computed during the $\mathrm{P}_{2} \mathrm{~N}_{2}$ component of the RotEP. The $t$-test analysis did not reveal significant effect when correcting for multiple comparisons (FDR correction). aPFC, anterior prefrontal cortex; dIPFC, dorsolateral prefrontal cortex; dPMA, dorsal premotor area; LOC, lateral occipital cortex; PPC, posterior parietal cortex; SMC, supplementary motor cortex.

The increased activation observed in the Updating task during the $\mathrm{N}_{1} \mathrm{P}_{2}$ interval persisted in several cortical regions during the last RotEP component $\left(\mathrm{P}_{2} \mathrm{~N}_{2}\right.$, between 303 and $470 \mathrm{~ms}$ after rotation onset). This was the case for the bilateral dlPFC, SMC, medial TC, and for the right PPC (see Figure 7). Other regions showed significant task-related activities exclusively in this last analyzed interval of the RotEP. These regions were the right dorsal premotor areas, the left and right cuneus, the left precuneus, and the left PPC. Increased in the Updating task during $\mathrm{N}_{1} \mathrm{P}_{2}$, the activity of the right temporal lobe was no longer altered by the spatial updating processes during $\mathrm{P}_{2} \mathrm{~N}_{2}$. The left LOC continued to exhibit greater activities in the Control task.

It is of note that the motor cortex contralateral to the arm used by the participants to point toward the home position after 
TABLE 1 | Maxima of regions showing significant differences between the Updating and control locations in the source space during the component P1N1 of the RotEP.

\begin{tabular}{lllllll}
\hline Location & \multicolumn{3}{c}{ MNI coordinates } & & T-statistics & $\begin{array}{c}\text { Brodmann } \\
\text { area }\end{array}$ \\
\cline { 2 - 4 } & X & Y & $\mathrm{Z}$ & & \\
\hline
\end{tabular}

\section{Left hemisphere}

PPC $-35$ $-60$ 51 $-3.09$

BA 39

TABLE 2 | Maxima of regions showing significant differences between the Updating and control locations in the source space during the component N1P2 of the RotEP.

\begin{tabular}{|c|c|c|c|c|c|}
\hline \multirow[t]{2}{*}{ Location } & \multicolumn{3}{|c|}{ MNI coordinates } & \multirow[t]{2}{*}{$T$-statistics } & \multirow{2}{*}{$\begin{array}{c}\text { Brodmann } \\
\text { area }\end{array}$} \\
\hline & $x$ & $\mathbf{Y}$ & $\mathbf{Z}$ & & \\
\hline
\end{tabular}

\begin{tabular}{lrrrrr}
\hline Left hemisphere & & & & & \\
dIPFC & -15 & 48 & 47 & 3.47 & BA 8 \\
Medial PFC & -13 & 47 & 10 & 2.77 & BA 10 \\
Rostral medial PFC & -5 & 55 & -6 & 2.51 & BA 10 \\
SMA & -4 & 6 & 44 & 3.77 & BA 6 \\
Medial temporal & -28 & -32 & -25 & 2.70 & BA 37 \\
Lateral occipital & -29 & -79 & 19 & -3.17 & BA 19 \\
Right hemisphere & & & & & \\
dIPFC & 7 & 51 & 46 & 3.19 & BA9 \\
Rostral medial PFC & 5 & 70 & 7 & 2.50 & BA10 \\
Rostral PFC & 30 & 55 & 25 & 2.83 & BA 10 \\
SMA & 9 & 2 & 53 & 3.35 & BA 6 \\
Temporal & 69 & -18 & -6 & 4.71 & BA 22 \\
Medial temporal & 28 & -29 & -22 & 3.69 & BA 37 \\
\hline
\end{tabular}

rotation did not show significant activity in any of the three analyzed intervals. This suggests that the increased activation observed in the present Updating task was more related to spatial updating than to motor preparation per se.

\section{DISCUSSION}

The present study was designed to gain insight into the dynamics of the cortical activations underpinning spatial updating during body motions. We used a protocol in which seated participants indicated their initial orientation after being passively rotated by different amplitudes in the dark. By contrasting, in successive time windows, the EEG activity recorded during body rotations from the EEG activity recorded in a baseline control task, we were able to isolate a discrete set of cortical areas involved in spatial updating processes and appraised their dynamics.

\section{The Early Processing of Rotation-Related Cues Is Largely Independent of the Spatial Updating}

As a first salient finding, the current measured in the source space remained largely similar between the Updating and Control tasks over the first component of the RotEPs, a period spanning 47-136 ms after body rotation onset. The only significant effect
TABLE 3 | Maxima of regions showing significant differences between the Updating and control locations in the source space during the component P2N2 of the RotEP.

\begin{tabular}{|c|c|c|c|c|c|}
\hline \multirow[t]{2}{*}{ Location } & \multicolumn{3}{|c|}{ MNI coordinates } & \multirow[t]{2}{*}{$T$-statistics } & \multirow{2}{*}{$\begin{array}{c}\text { Brodmann } \\
\text { area }\end{array}$} \\
\hline & $\mathbf{x}$ & $\mathbf{Y}$ & $\mathbf{Z}$ & & \\
\hline \multicolumn{6}{|l|}{ Left hemisphere } \\
\hline dIPFC & -7 & 52 & 44 & 2.49 & BA 9 \\
\hline dIPFC & -2 & 24 & 51 & 3.24 & BA 8 \\
\hline Medial PFC & -2 & 50 & 45 & 2.44 & BA 9 \\
\hline Medial PFC & 3 & 17 & 50 & 3.03 & BA 8 \\
\hline Rostral medial PFC & -5 & 55 & -4 & 2.51 & BA 10 \\
\hline SMA & -1 & 0 & 56 & 3.76 & BA 6 \\
\hline Medial temporal & -24 & -30 & -25 & 2.71 & BA 37 \\
\hline Temporal & -47 & 1 & -41 & 2.40 & BA 20 \\
\hline PPC & -24 & -61 & 61 & 3.24 & $\mathrm{BA} 7$ \\
\hline Precuneus & -1 & -78 & 46 & 2.6 & BA 7 \\
\hline Occipital & -1 & -94 & 19 & 4.83 & BA 18 \\
\hline Lateral occipital & -34 & -93 & 17 & -2.83 & BA 19 \\
\hline \multicolumn{6}{|c|}{ Right hemisphere } \\
\hline dIPFC & 5 & 51 & 45 & 2.61 & BA 9 \\
\hline dIPFC & 8 & 34 & 61 & 3.24 & BA 8 \\
\hline Medial PFC & 3 & 49 & 39 & 2.40 & BA 9 \\
\hline Medial PFC & 3 & 24 & 53 & 3.14 & BA 8 \\
\hline SMA & 4 & -7 & 61 & 3.97 & BA 6 \\
\hline Premotor & 16 & -16 & 77 & 3.61 & BA 6 \\
\hline Medial temporal & 23 & -2 & -40 & 2.86 & BA 20 \\
\hline PPC & 18 & -46 & 80 & 3.84 & BA 7 \\
\hline Occipital & 2 & -87 & 19 & 4.65 & BA 18 \\
\hline
\end{tabular}

revealed by the statistical map during this interval was a smaller activation in the Updating task in a few vertices of the left PPC and LOC. This effect persisted at both mid- and long latencies only for the LOC. The narrowness of the regions showing this trend raises the question of the robustness of this finding. Note, however, that the LOC contributes to the allocentric coding of space (Committeri et al., 2004; Zaehle et al., 2007; Ruotolo et al., 2019). Hence, the smaller activity observed in the LOC during the Updating task may have hampered the use of this frame of reference for encoding home position during body rotations. This could have indirectly enhanced the use of an egocentric frame of reference, which appeared more relevant in the present Updating task performed in the dark.

The absence of large task-related activation during $\mathrm{P}_{1} \mathrm{~N}_{1}$ suggests that the first wave of idiothetic cue processing during the body rotations was not strictly linked to spatial updating. Yet, despite their non-specific nature, brain processes during the early phase of the rotations most certainly remained critical for spatial updating. This could be the case of the processes associated to vestibular inputs, which are the main carrier of body motion information during passive displacements in the dark (Valko et al., 2012).

The scarcity of early task-related activation was somewhat unexpected given that overt and covert attention influences neural activities related to the early processing of sensory cues (<100 ms; Woldorff et al., 1987; Di Russo and Spinelli, 1999). 
One explanation for the lack of different cortical activations between the Updating and Control tasks may be that participants also directed their attention toward self-motion information in the latter task. This could have helped them to keep fixation on the chair-fixed LED during the rotations.

\section{Evidence of Processes Related to Spatial Working Memory and Spatial Updating at Mid-Latencies}

Large significant task-related activities emerged during the second RotEP component (i.e., $\mathrm{N}_{1} \mathrm{P}_{2}, 136-303 \mathrm{~ms}$ after rotation onset). These activities were source-localized in a large network comprised mainly of the frontal, temporal and parietal regions. Like most task-related activities observed in the present study, the current measured in these regions were greater in the Updating than in the Control tasks.

The dlPFC and mPFC showed increased activations in the Updating task. The increased activations in these frontal areas could be associated to important executive functions for spatial processes. Their roles in maintaining spatial information in short-term working memory, and in the cognitive manipulation of information from the environment that is out of view (Wager and Smith, 2003; Gilbert and Burgess, 2008) could have been relevant in the present study for keeping track of the original orientation during entire body rotations. The persistence, in the last analyzed interval, of the strong activity of the dlPFC and $\mathrm{mPFC}$ in the Updating task is consistent with this suggestion.

On the other hand, the task-related activations observed in the aPFC and TC at both mid- and long latencies could be linked to the online processing of home direction during rotations. This interpretation is supported both by human studies showing that the aPFC is crucial to encoding spatial information about goals (Ekstrom et al., 2003; Ciaramelli, 2008; Spiers, 2008; see Poucet and Hok, 2017 for similar evidence in rodents) and by those reporting that the activities of the medial temporal lobe dynamically change according to the current Euclidean distance of the spatial goal during navigation (Ekstrom et al., 2003; Howard et al., 2014; Spiers and Barry, 2015; Kunz et al., 2021). Together, the sustained activation observed in the prefrontal and temporal regions while participants were passively rotated could have then contributed to the maintenance of home orientation in working memory and in the encoding of its angular distance for use in the upcoming goal-directed pointing movements.

We also found significant increased activities in the Updating task in the right superior PPC during $\mathrm{N}_{1} \mathrm{P}_{2}$ which became bilateral during $\mathrm{P}_{2} \mathrm{~N}_{2}$. These results were to be expected given the well-recognized importance of the superior PPC for spatial processes, including those specifically linked to the updating of spatial representations during movements (Duhamel et al., 1992; Medendorp et al., 2003; Merriam et al., 2003; Pisella and Mattingley, 2004; Ventre-Dominey and Vallee, 2007; Gutteling et al., 2015; Gutteling and Medendorp, 2016). The activity of the PPC could have contributed to estimating the angle of home position during and after body rotation (Spiers and Maguire, 2007; Howard et al., 2014; see Ekstrom et al., 2017 for a review), which was an important egocentric process for planning the pointing movement.

The increased activation observed in the superior PPC could also be related to the maintenance of spatial attention (see Ikkai and Curtis, 2011, for a review), which is a critical cognitive process for spatial updating. It should be noted that our observation that the increased activity in the right PPC preceded the increased activity over the left PPC is consistent with studies suggesting a right-hemispheric dominance for visual processes and remapping (Corbetta et al., 2000; Marshall and Fink, 2001; Pisella et al., 2011).

The SMC was the last region where significant taskdependent activities were observed at mid-latencies. These increased activities also lasted until the final analysis time window (i.e., $\mathrm{P}_{2} \mathrm{~N}_{2}$ ). The SMC comprises the supplementary motor area (SMA), the supplementary eye fields (SEF) and the presupplementary motor area (preSMA) (Nachev et al., 2008). The SEF might have played a crucial role in the Updating task. This is suggested by studies showing that lesions affecting the SEF impair the accuracy of saccades toward a memorized visual target only if the patients are rotated before triggering the saccade (PierrotDeseilligny et al., 1993, 1995). The SEF was first considered as an oculomotor area (Schlag and Schlag-Rey, 1987). Studies in Monkey, however, have identified a large population of SEF neurons that increase their activities during arm movements (40\% of 337 neurons in Fujii et al., 2001; 42\% of 106 neurons in Mushiake et al., 1996). These arm-related cells provide grounds for a plausible contribution of the SEF to providing relevant spatial information in the present study for pointing, after the rotations, toward the original body orientation.

\section{Long-Latency Activities During Spatial Updating Could Be Linked to Spatial Representations}

Bilateral increased activations were observed at long-latency $\left(\mathrm{P}_{2} \mathrm{~N}_{2}\right)$ in the cuneus, which is part of the medial visual cortex. In the present study, the only available visual input was a chairfixed LED which the participants fixated throughout the trials. Because this visual input was present in both tasks, the contrast of Updating and Control tasks most likely canceled out the neural activity evoked by the LED fixation. This possibility is well supported by the fact that the latency of the task-related activity observed in the cuneus (>300 ms) was much longer than the latency of visual-evoked potentials recorded in occipital lobe either by EEG or magnetoencephalography ( $<80 \mathrm{~ms}$, Vianni et al., 2001; Ellemberg et al., 2003; Lebar et al., 2015). More likely, the late activity of the visual cortex may have resulted from nonvisual top-down signals (mediated for instance by parietal or frontal regions, Michelli et al., 2004). This could have enabled the use of a visual-like representation to encode initial direction during the rotation, perhaps through visual mental imagery (see Kosslyn et al., 1999; Strokes et al., 2009). The fact that visual mental imagery activates the earliest visual cortex (BA 17 and 18) (Slotnick et al., 2005) affords this possibility.

It is interesting to note that the task-related activities observed in the medial surface of the left PPC (i.e., precuneus) at 
long latencies are consistent with the use of an egocentric frame of reference for encoding home position (Byrne et al., 2007; Wolbers et al., 2008; Chadwick et al., 2015). Based on idiothetic and gaze direction cues (Paillard, 1987; Jeannerod, 1991), this frame of reference appears most relevant in the present spatial task for updating body orientation during rotations in the dark. The egocentric spatial information contained in the precuneus would serve in contexts with body displacement but not for the mere egocentric judgments of objects location in steady body conditions (Chadwick et al., 2015). We noted that the increased activation of the precuneus observed in the Updating task was left lateralized. This lateralization was also found by Chadwick et al. (2015) when using searchlight analysis to characterize neural activity in an fMRI navigation study, but not in their follow-up analyses using a more liberal threshold. Bilateral activation of the precuneus was also observed in the Wolbers et al.'s (2008) fMRI study when participants indicated the position of memorized objects following selfdisplacements in virtual environments. Note, however, that the low temporal resolution of fMRI scanners does not allow to determine whether activations in both hemispheres occur simultaneously. The results of the present EEG study may suggest that processes related to egocentric representations may have shorter latencies in the left than in the right precuneus, especially when encoding spatial positions from the contralateral visual hemifield.

Dorsal motor areas of the frontal lobe were strongly activated in the last analyzed rotation interval of the Updating task. These areas have direct connections with spinal motor neurons (Chouinard and Paus, 2009). Importantly, however, we found that the increased activations in the dorsal motor areas were circumscribed to the right hemisphere, which was ipsilateral to the pointing arm. Although a fraction of ipsilateral connections reaches the spinal level (Kuypers, 1981), the absence of significant task-related activities in the contralateral dorsal motor areas suggests that the functions linked to their activations were more cognitive than motoric in nature. The marked activities found in the right $\mathrm{APMC}$ in the Updating task is consistent with studies showing evidence of functional hemispheric differences between the left and right $\mathrm{APMC}$, with a salience for the right $\mathrm{dPMC}$ for spatial working memory processes (Jonides et al., 1993; Smith and Jonides, 1999). The dPMC could have beneficiated from inputs sent by prefrontal areas which showed task-related activities with shorter latencies (136-303 ms vs. 303-470 $\mathrm{ms}$ after rotation onset). Indeed, the $\mathrm{dPMC}$, and particularly the areas with only sparse projections to motoneurons, have dense connections with the PFC ( $\mathrm{Lu}$ et al., 1994; Genon et al., 2017).

\section{Enhanced $\mathrm{P}_{1} \mathrm{~N}_{\mathbf{1}}$ Amplitude During Relevant Idiothetic Stimulation}

The $\mathrm{P}_{1} \mathrm{~N}_{1}$ component of the RotEP, as measured here over the vertex, had a significantly greater amplitude when the participants had to update their orientation during body rotations. This finding indicates that the amplitude of the cortical potential recorded at scalp level is a reliable marker of cognitive process enhancement related to spatial updating (including processes related to attention). This task-related effect on the $\mathrm{P}_{1} \mathrm{~N}_{1}$ amplitude has found little echo, however, in the cortical current measured in the source space during the same $\mathrm{P}_{1} \mathrm{~N}_{1}$ interval. This could be explained by the fact that the latter variable was obtained by averaging the cortical current over the $\mathrm{P}_{1} \mathrm{~N}_{1}$ interval and that $\mathrm{N}_{1}$ marked the upper bound of this interval. The differential effect of the updating task on these two EEG measurements (i.e., $\mathrm{P}_{1} \mathrm{~N}_{1}$ amplitude and current in the $\mathrm{P}_{1} \mathrm{~N}_{1}$ interval) might suggest that the processes specifically dedicated to space updating essentially started with a latency close to that of $\mathrm{N}_{1}$, measured here as $136 \mathrm{~ms}$ after body rotation. Computing this latency with respect to the first cortical arrival of idiothetic cues (i.e., $\mathrm{P}_{1}$ : $47 \mathrm{~ms}$ after rotation onset), probably provides a better estimate of the latency of the updating processes. Viewed from this perspective, our EEG recordings suggest that the cortical processes specifically involved in spatial updating have a latency of $\sim 89 \mathrm{~ms}$.

Ertl et al. (2017) reported that the amplitude of the first RotEP component increases by increasing linear acceleration of the participants. In the present study, despite the angular acceleration increased with the rotation amplitude (see Figure 2), the amplitude of $\mathrm{P}_{1} \mathrm{~N}_{1}$ did not significantly differ between the different body accelerations. Although it is difficult to compare linear and angular accelerations, one can notice that the maximal linear accelerations differed more between the different translation conditions in Ertl et al.'s (2017) study (from 1 to 7.67 times greater) than the maximal angular accelerations did between the different rotation conditions of the current study (from 1 to 1.36 times greater). Hence, the absence of effect of angular acceleration on the amplitude of the RotEP could be due to the small difference of acceleration, in the present study, between the $20^{\circ}, 30^{\circ}$, and $40^{\circ}$ rotation amplitudes.

\section{Limitations}

Some limitations in the present study should be considered. Having the objective that task-related cortical activities observed in the Updating task could not merely reflect motor-related processes linked to the preparation of the pointing movements produced after body rotations, we restrained our analyses to the early spatial updating processes [i.e., <470 $\mathrm{ms}\left(\mathrm{N}_{2}\right)$ with respect to the onset of body rotation]. Cortical activities involved in spatial updating that had greater latencies could therefore not be identified. Also, because the present vestibular memorycontingent task involved goal-directed arm movements, taskrelated activities observed here could be, in part, specific to spatial updating in contexts of motor actions, and perhaps more specifically of goal-directed arm movements.

Another limitation concerns the statistical analyses of the cortical sources. The present experiment was designed to investigate the dynamics of the cortical activation (including from inner surfaces) during spatial updating. To enhance the spatial resolution of the brain template, we used a high number of vertices (i.e., 306,716 vertices), without correcting for multiple comparisons. Further studies could build on the present results to focus the analyses on more circumscribed regions of the cortical 
network shown here as being involved in spatial updating, allowing for multiple comparisons corrections.

\section{CONCLUSION}

The excellent temporal resolution of the EEG recordings combined with the enhanced spatial resolution of EEG data by sources analyses allowed us to obtain insight into the dynamics of spatial updating during body motions. Within the time window of our analyses (period spanning 47-470 ms after body rotation onset), virtually all task-related cortical changes of cortical activities during spatial updating involved increased rather than decreased activations. We found that the cortical activities specifically related to spatial updating during body rotation started $\sim 90 \mathrm{~ms}$ after the first arrival of idiothetic inputs to the cortex. The spatial updating processes were largely mediated by a fronto-temporo-posterior network and implicated more regions of the right hemisphere. Among the first cortical regions showing task-related activities were those that contribute to the encoding of spatial goals and to spatial working memory processes (e.g., aPFC, dlPFC, TC). The regions showing later taskrelated activities are known to be involved in the visual processing and in the egocentric representation of the environment (e.g., cuneus, precuneus). Because the spatial updating processes investigated here served as a basis for planning goal-directed arm movements, in future research, it will be interesting to contrast the present results with those obtained in tasks requiring other motor outputs (e.g., saccade, locomotion) or pure cognitive estimates of object locations during or after body displacements. It will also be necessary to determine the degree to which the right-hemispheric dominance for spatial updating revealed here persists for rightward body rotations.

\section{REFERENCES}

Baillet, S., Mosher, J. C., and Leahy, R. M. (2001). Electromagnetic brain mapping. IEEE Signal Process. Mag. 18:6. doi: 10.1109/79.962275

Balaguer, J., Spiers, H., Hassabis, D., and Summerfield, C. (2016). Neural mechanisms of hierarchical planning in a virtual subway network. Neuron 90, 893-903. doi: 10.1016/j.neuron.2016.03.037

Blouin, J., Guillaud, E., Bresciani, J. P., Guerraz, M., and Simoneau, M. (2010). Insights into the control of arm movement during body motion as revealed by EMG analyses. Brain Res. 1309, 40-52. doi: 10.1016/j.brainres.200910.063

Blouin, J., Labrousse, L., Simoneau, M., Vercher, J. L., and Gauthier, G. M. (1998). Updating visual space during passive and voluntary head-in-space movements. Exp. Brain Res. 122, 93-100. doi: 10.1007/s002210050495

Blouin, J., Saradjian, A. H., Pialasse, J.-P., Manson, G. A., Mouchnino, L., and Simoneau, M. (2019). Two neural circuits to point towards home position after passive body displacements. Front. Neural Circuits 13:70. doi: 10.3389/fncir. 2019.00070

Blouin, J., Vercher, J.-L., Gauthier, G. M., Paillard, J., Bard, C., and Lamarre, Y. (1995). Perception of passive whole-body rotation in the absence of neck and body proprioception. J. Neurophysiol. 74, 2216-2219. doi: 10.1152/jn.1995.74.5. 2216

Boon, P. J., Zeni, S., Theeuwes, J., and Belopolsky, A. V. (2018). Rapid updating of spatial working memory across saccades. Sci. Rep. $8: 1072$. doi: 10.1038/s41598017-18779-9

Brandt, T., Schautzer, F., Hamilton, D. A., Brüning, R., Markowitsch, H. J., Kalla, R., et al. (2005). Vestibular loss causes hippocampal atrophy and impaired spatial memory in humans. Brain 128, 2732-2741. doi: 10.1093/brain/awh617

\section{DATA AVAILABILITY STATEMENT}

The raw data supporting the conclusions of this article will be made available by the authors, without undue reservation.

\section{ETHICS STATEMENT}

The studies involving human participants were reviewed and approved by Laval University Biomedical Ethics Committee. The patients/participants provided their written informed consent to participate in this study.

\section{AUTHOR CONTRIBUTIONS}

JB: conceptualization, methodology, investigation, data processing, data curation, writing-original draft preparation, reviewing, and validation. J-PP: conceptualization, methodology, software, and validation. LM: conceptualization, methodology, reviewing, and validation. MS: conceptualization, methodology, software, investigation, data processing, writing, reviewing, and validation. All authors: contributed to the article and approved the submitted version.

\section{FUNDING}

This research was supported by grants from the Natural Sciences and Engineering Research Council of Canada to MS (grant \#04068) and by the French Agence Nationale de la Recherche (ANR) to JB and LM (ANR-14-CE30-007-02).

Byrne, P., Becker, S., and Burgess, N. (2007). Remembering the past and imagining the future: a neural model of spatial memory and imagery. Psychol. Rev. 114, 340-375. doi: 10.1037/0033-295X.114.2.340

Chadwick, M. J., Jolly, A. E., Amos, D. P., Hassabis, D., and Spiers, H. J. (2015). A goal direction signal in the human entorhinal/subicular region. Curr. Biol. 25, 87-92. doi: 10.1016/j.cub.2014.11.001

Chand, G. B., and Dhamala, M. (2017). Interactions between the anterior cingulateinsula network and the fronto-parietal network during perceptual decisionmaking. Neuroimage 152, 381-389. doi: 10.1016/j.neuroimage.2017.03.014

Chouinard, P. A., and Paus, T. (2009). The primary motor and premotor areas of the human cerebral cortex. Neuroscientist 12, 143. doi: 10.1177/ 1073858405284255

Ciaramelli, E. (2008). The role of ventromedial prefrontal cortex in navigation: a case of impaired wayfinding and rehabilitation. Neuropsychologia 46, 20992105. doi: 10.1016/j.neuropsychologia.2007.11.029

Committeri, G., Galati, G., Paradis, A. L., Pizzamiglio, L., Berthoz, A., and LeBihan, D. (2004). Reference frames for spatial cognition: different brain areas are involved in viewer-, object-, and landmark-centered judgments about object location. J. Cogn. Neurosci. 16, 1517-1535. doi: 10.1162/0898929042568550

Corbetta, M., and Shulman, G. L. (2002). Control of goal-directed and stimulusdriven attention in the brain. Nat. Rev. Neurosci. 3, 201-215. doi: 10.1038/ nrn755

Corbetta, M., Kincade, J. M., Ollinger, J. M., McAvoy, M. P., and Shulman, G. L. (2000). Voluntary orienting is dissociated from target detection in human posterior parietal cortex. Nat. Neurosci. 3, 292-297. doi: 10.1038/73009

Cybulska-Klosowicz, A., Meftah, E.-M., Raby, M., Lemieux, M. L., and Chapman, C. E. (2011). A critical speed for gating of tactile detection during 
voluntary movement. Exp. Brain Res. 210, 291-301. doi: 10.1007/s00221-011-2 632-0

Di Russo, F., and Spinelli, D. (1999). Electrophysiological evidence for an early attentional mechanism in visual processing in humans. Vision Res. 39, 29752985. doi: 10.1016/S0042-6989(99)00031-0

Duhamel, J.-R., Colby, C. L., and Goldberg, M. E. (1992). The updating of the representation of visual space in parietal cortex by intended eye movements. Science 255, 90-92. doi: 10.1126/science.1553535

Ekstrom, A. D., Huffman, D. J., and Starrett, M. (2017). Interacting networks of brain regions underlie human spatial navigation: a review and novel synthesis of the literature. J. Neurophysiol. 118, 3328-3344. doi: 10.1152/jn.00531.2017

Ekstrom, A. D., Kahana, M. J., Caplan, J. B., Fields, T. A., Isham, E. A., Newman, E. L., et al. (2003). Cellular networks underlying human spatial navigation. Nature 425, 184-188. doi: 10.1038/nature01964

Ellemberg, D., Lavoie, K., Lewis, T. L., Maurer, D., Lepore, F., and Guillemot, J.-P. (2003). Longer VEP latencies and slower reaction times to the onset of secondorder motion than to the onset of first-order motion. Vision Res. 43, 651-658. doi: 10.1016/S0042-6989(03)00006-3

Ertl, M., and Boegle, R. (2019). Investigating the vestibular system using modern imaging techniques -a review on the available stimulation and imaging methods. J. Neurosci. Methods 326:108363. doi: 10.1016/j.jneumeth.2019. 108363

Ertl, M., Moser, M., Boegle, R., Conrad, J., Zu Eulenburg, P., and Dieterich, M. (2017). The cortical spatiotemporal correlate of otolith stimulation: vestibular evoked potentials by body translations. Neuroimage $155,50-59$. doi: 10.1016/j. neuroimage.2017.02.044

Fujii, N., Mushiake, H., and Tanji, J. (2001). Distribution of eye- and armmovement-related neuronal activity in the SEF and in the SMA and Pre-SMA of Monkeys. J. Neurophysiol. 87, 2158-2166. doi: 10.1152/jn.00867.2001

Funabiki, K., and Naito, Y. (2002). Validity and limitation of detection of peripheral vestibular imbalance from analysis of manually rotated vestibulo-ocular reflex recorded in the routine vestibular clinic. Acta Otolaryngol. 122, 31-36. doi: $10.1080 / 00016480252775706$

Gale, S., Prsa, M., Schurger, A., Gay, A., Paillard, A., Herbelin, B., et al. (2016). Oscillatory neural responses evoked by natural vestibular stimuli in humans. J. Neurophysiol. 115, 1228-1242. doi: 10.1152/jn.00153.2015

Genon, S., Li, H., Fan, L., Müller, V. I., Cieslik, E. C., Hoffstaedter, F., et al. (2017). The right dorsal premotor mosaic: organization, functions, and connectivity. Cereb. Cortex 27, 2095-2110. doi: 10.1093/cercor/bhw065

Ghuman, A. S., and Martin, A. (2019). Dynamic neural representations: an inferential challenge for fMRI. Trends Cogn. Sci. 23, 534-536. doi: 10.1016/j. tics.2019.04.004

Gilbert, S. J., and Burgess, P. (2008). Execution function. Curr. Biol. 18, R110-R114. doi: $10.1016 /$ j.cub.2007.12.014

Gramfort, A., Papadopoulo, T., Olivi, E., and Clerc, M. (2010). OpenMEEG: open source software for quasistatic bioelectromagnetics. BioMed. Eng. Online 9:45. doi: 10.1186/1475-925X-9-45

Gutteling, T. P., and Medendorp, W. P. (2016). Role of alpha-band oscillations in spatial updating across whole body motion. Front. Psychol 7:671. doi: 10.3389/ fpsyg.2016.00671

Gutteling, T. P., Selen, L. P. J., and Medendorp, W. (2015). Parallax-sensitive remapping of visual space in occipito-parietal alpha-band activity during whole-body motion. J. Neurophysiol. 113, 1574-1584. doi: 10.1152/jn.00477. 2014

Hanson, J. M., and Goebel, J. A. (1998). Comparison of manual whole-body and passive and active head-on-body rotational testing with conventional rotary chair testing. J. Vestib. Res. 8, 273-282. doi: 10.3233/VES-1998-8307

Hartley, T., Maguire, E. A., Spiers, H. J., and Burgess, N. (2003). The well-worn route and the path less travelled: distinct neural bases of route following and wayfinding in humans. Neuron 37, 877-888. doi: 10.1016/S0896-6273(03) 00095-3

Hodgson, E., and Waller, D. (2006). Lack of set size effects in spatial updating: evidence for offline updating. J. Exp. Psychol. Learn. Mem. Cogn. 32, 854-866. doi: 10.1037/0278-7393.32.4.854

Howard, L. R., Javadi, A. H., Yu, Y., Mill, R. D., Morrison, L. C., Knight, R., et al. (2014). The hippocampus and entorhinal cortex encode the path and Euclidean distances to goals during navigation. Curr. Biol. 24, 1331-1340. doi: 10.1016/j.cub.2014.05.001
Ikkai, A., and Curtis, C. E. (2011). Common neural mechanisms supporting spatial working memory, attention and motor intention. Neuropsychologia 49 , 1428-1434. doi: 10.1016/j.neuropsychologia.2010.12.020

Im, C. H., Gururajan, A., Zhang, N., Chen, W., and He, B. (2007). Spatial resolution of EEG cortical source imaging revealed by localization of retinotopic organization in human primary visual cortex. J. Neurosci. Methods 161, 142154. doi: 10.1016/j.jneumeth.2006.10.008

Jasper, H. H., and Penfield, W. (1949). Electrocorticograms in man: effect of voluntary movement upon the electrical activity of the precentral gyrus. Arch. Psychiatr. Z. Neurol. 183, 163-174. doi: 10.1007/BF01062488

Jeannerod, M. (1991). "The interaction of visual and proprioceptive cues in controlling reaching movements," in Motor Control: Concepts and Issues, eds D. R. Humphrey and H.-J. Freund (New York, NY: Wiley), 277-291.

Jonides, J., Smith, E. E., Koeppe, R. A., Awh, E., Minoshima, S., and Mintun, M. A. (1993). Spatial working memory in humans as revealed by PET. Nature 363, 623-625. doi: 10.1038/363623a0

Klier, E. M., and Angelaki, D. E. (2008). Spatial updating and the maintenance of visual constancy. Neuroscience 156, 801-818. doi: 10.1016/j.neuroscience.2008. 07.079

Kosslyn, S. M., Pascual-Leone, A., Felician, O., Camposano, S., Keenan, J. P., Ganis, G., et al. (1999). The role of area 17 in visual imagery: convergent evidence from PET and rTMS. Science 284, 167-170. doi: 10.1126/science.284.5411.167

Kremmyda, O., Hüfner, K., Flanagin, V. L., Hamilton, D. A., Linn, J., Strupp, M., et al. (2016). Beyond dizziness: virtual navigation, spatial anxiety and hippocampal volume in bilateral vestibulopathy. Front. Hum. Neurosci. 10:139. doi: 10.3389/fnhum.2016.00139

Kunz, L., Brandt, A., Reinacher, P. C., Staresina, B. P., Reifenstein, E. T., Weidemann, C. T., et al. (2021). A neural code for egocentric spatial maps in the human medial temporal lobe. Neuron 109, 2781-2796.e10. doi: 10.1016/j. neuron.2021.06.019

Kuypers, H. G. J. M. (1981). "Anatomy of the descending pathways," in Handbook of physiology, eds V. B. Brooks, J. M. Brookhart, and V. B. Mountcastle (Bethesda, MD: The American Physiological Society), 597-666.

Lacadie, C. M., Fulbright, R. K., Constable, R. T., and Papademetris, X. (2008a). More accurate Talairach coordinates for neuroimaging using nonlinear registration. Neuroimage 42, 717-725. doi: 10.1016/j.neuroimage.2008.04.240

Lacadie, C., Fulbright, R. K., Arora, J., Constable, R., and Papademetris, X. (2008b). "Brodmann areas defined in MNI space using a new tracing tool in BioImage suite," in Proceedings of the 14th Annual Meeting of the Organization for Human Brain Mapping, Vol. 771, Melbourne, VIC.

Lebar, N., Bernier, P. M., Guillaume, A., Mouchnino, L., and Blouin, J. (2015). Neural correlates for task-relevant facilitation of visual inputs during visually guided hand movements. Neuroimage 121, 39-50. doi: 10.1016/j.neuroimage. 2015.07.033

Lu, M.-T., Preston, J. B., and Strick, P. L. (1994). Interconnections between the prefrontal cortex and the premotor areas in the frontal lobe. J. Comparat. Neurol. 341, 375-392. doi: 10.1002/cne.903410308

Mackrous, I., Carriot, J., and Simoneau, M. (2019). Learning to use vestibular sense for spatial updating is context dependent. Sci. Rep. $9: 11154$. doi: 10.1038/ s41598-019-47675-7

Marshall, J. C., and Fink, G. R. (2001). Spatial cognition: where we were and where we are. Neuroimage 14, S2-S7. doi: 10.1006/nimg.2001.0834

Medendorp, W. P. (2011). Spatial constancy mechanisms in motor control. Philos. Trans. R. Soc. B Biol. Sci. 366, 476-491. doi: 10.1098/rstb.2010. 0089

Medendorp, W. P., and Selen, L. J. P. (2017). Vestibular contributions to highlevel sensorimotor functions. Neuropsychologia 105, 144-152. doi: 10.1016/j. neuropsychologia.2017.02.004

Medendorp, W. P., Goltz, H. C., Vilis, T., and Crawford, J. D. (2003). Gaze centered updating of visual space in human parietal cortex. J. Neurosci. 23, 6209-6214. doi: 10.1523/jneurosci.23-15-06209.2003

Merriam, E. P., Genovese, C. R., and Colby, C. L. (2003). Spatial updating in human parietal cortex. Neuron 39, 361-373. doi: 10.1016/S0896-6273(03)0 0393-3

Michelli, A., Price, C. J., Friston, K. J., and Ishai, A. (2004). Where bottom-up meets top-down: neuronal interactions during perception and imagery. Cereb. Cortex 14, 1256-1265. doi: 10.1093/cercor/bhh087 
Mushiake, H., Fujii, N., and Tanji, J. (1996). Visually guided saccade versus eyehand reach: contrasting neuronal activity in the cortical supplementary and frontal eye fields. J. Neurophysiol. 75, 2187-2191. doi: 10.1152/jn.1996.75.5.2187

Nachev, P., Kennard, C., and Husain, M. (2008). Functional role of the supplementary and pre-supplementary motor areas. Nat. Rev. Neurosci. 9, 856-869. doi: 10.1038/nrn2478

Nemmi, F., Piras, F., Péran, P., Incoccia, C., Sabatini, U., and Guariglia, C. (2013). Landmark sequencing and route knowledge: an fMRI study. Cortex 49, 507-519. doi: 10.1016/j.cortex.2011.11.016

Nolan, H., Whelan, R., Reilly, R., Bulthoff, H. H., and Butler, J. S. (2009). "Acquisition of human EEG data during linear self motion on a Stewart platform," in Proceedings of the IEEE EMBS Conference Neural Engineering (Antalya: IEEE), 1-4. doi: 10.1109/NER.2009.5109364

Paillard, J. (1987). "Cognitive versus sensorimotor encoding of spatial information," in Cognitive Processes and Spatial Orientation in Animal and Man, eds P. Ellen and C. Thinus-Blanc (Dordrecht: Martinus Nijhoff), $1-34$.

Pataky, T. C., Robinson, M. A., and Vanrenterghem, J. (2013). Vector field statistical analysis of kinematic and force trajectories. J. Biomech. 46, 2394-2401. doi: 10.1016/j.jbiomech.2013.07.031

Pfurtscheller, G., and Lopes da Silva, F. H. (1999). Event-related EEG/MEG synchronization and desynchronization: basic principles. Clin. Neurophysiol. 110, 1842-1857. doi: 10.1016/S1388-2457(99)00141-8

Pierrot-Deseilligny, C., Rivaud, S., Gaymard, B., Müri, R., and Vermersch, A. I. (1995). Cortical control of saccades. Ann. Neurol. 37, 557-567. doi: 10.1002/ ana.410370504

Pierrot-Deseilligny, C., Israël, I., Berthoz, A., Rivaud, S., and Gaymard, B. (1993). Role of the different frontal lobe areas in the control of the horizontal component of memory-guided saccades in man. Exp. Brain Res. 95, 166-171. doi: $10.1007 /$ bf00229665

Pisella, L., Alahyane, N., Blangero, A., Thery, F., Blanc, S., and Pélisson, D. (2011). Right-hemispheric dominance for visual remapping in humans. Philos. Trans. R. Soc. Lond. B Biol. Sci. 366, 572-585. doi: 10.1098/rstb.2010.0258

Pisella, L., and Mattingley, J. B. (2004). The contribution of spatial remapping impairments to unilateral visual neglect. Neurosci. Biobehav. Rev. 28, 181-200. doi: 10.1016/j.neubiorev.2004.03.003

Ponz, A., Montant, M., Liegeois-Chauvel, C., Silva, C., Braun, M., Jacobs, A. M., et al. (2014). Emotion processing in words: a test of the neural re-use hypothesis using surface and intracranial EEG. Soc. Cogn. Affect. Neurosci. 9, 619-627. doi: 10.1093/scan/nst034

Poucet, B., and Hok, V. (2017). Remembering goal locations. Curr. Opin. Behav. Sci. 17, 51-56. doi: 10.1016/j.cobeha.2017.06.003

Rieser, J. J. (1989). Access to knowledge of spatial structure at novel points of observation. J. Exp. Psychol. Learn. Mem. Cogn. 15, 1157-1165. doi: 10.1037/ 0278-7393.15.6.1157

Ruotolo, F., Ruggiero, G., Raemaekers, M., Iachini, T., van der Ham, I. J. M., Fracasso, A., et al. (2019). Neural correlates of egocentric and allocentric frames of reference combined with metric and non-metric spatial relations. Neuroscience 409, 235-252. doi: 10.1016/j.neuroscience.2019.04.021

Salmelin, R., and Baillet, S. (2009). Electromagnetic brain imaging. Hum. Brain Mapp. 30, 1753-1757. doi: 10.1002/hbm.20795

Saradjian, A. H., Tremblay, L., Perrier, J., Blouin, J., and Mouchnino, L. (2013). Cortical facilitation of proprioceptive inputs related to gravitational balance constraints during step preparation. J. Neurophysiol. 110, 397-407. doi: 10.1152/ jn.00905.2012

Schlag, J., and Schlag-Rey, M. (1987). Evidence for a supplementary eye field. J. Neurophysiol. 57, 179-200. doi: 10.1152/jn.1987.57.1.179

Schneider, D., Kolchev, C., Constantinescu, L., and Claussen, C. F. (1996). Vestibular evoked potentials (VestEP) and brain electrical activity mapping a test of vestibular function - a review (1990-1996). Int. Tinnitus J. 2, 27-43.

Schöberl, F., Pradhan, C., Grosch, M., Brendel, M., Jostes, F., Obermaier, K., et al. (2021). Bilateral vestibulopathy causes selective deficits in recombining novel routes in real space. Sci. Rep. 11 :2695. doi: 10.1038/s41598-021-82427-6

Seeck, M., Koessler, L., Bast, T., Leijten, F., Michel, C., Baumgartner, C., et al. (2017). The standardized EEG electrode array of the IFCN. Clin. Neurophysiol. 128, 2070-2077. doi: 10.1016/j.clinph.2017.06.254

Sherril, K. R., Chrastil, E. R., Ross, R. S., Erdem, U. M., Hasselmo, M. E., and Stern, C. E. (2015). Functional connections between optic flow areas and navigationally responsive brain regions during goal-directed navigation. Neuroimage 118, 86-396. doi: 10.1016/j.neuroimage.2015.06.009

Slotnick, S. D., Thompson, W. L., and Kosslyn, S. M. (2005). Visual mental imagery induces retinotopically organized activation of early visual areas. Cereb. Cortex 15, 1570-1583. doi: 10.1093/cercor/bhi035

Smith, E. E., and Jonides, J. (1999). Storage and executive processes in the frontal lobes. Science 283, 1657-1661. doi: 10.1126/science.283.5408.1657

Smith, P. (2017). The vestibular system and cognition. Curr. Opin. Neurol. 30, 84-89. doi: 10.1097/WCO.0000000000000403

Sohrabpour, A., Lu, Y., Kankirawatana, P., Blount, J., Kim, H., and He, B. (2015). Effect of EEG electrode number on epileptic source localization in pediatric patients. Clin. Neurophysiol. 126, 472-480. doi: 10.1016/j.clinph.2014.05.038

Spiers, H. J. (2008). Keeping the goal in mind: prefrontal contributions to spatial navigation. Neuropsychologia 46, 2106-2108. doi: 10.1016/j.neuropsychologia. 2008.01 .028

Spiers, H. J., and Barry, C. (2015). Neural systems supporting navigation. Curr. Opin. Behav. Sci. 1, 47-55. doi: 10.1016/j.cobeha.2014.08.005

Spiers, H. J., and Maguire, E. A. (2007). A navigational guidance system in the human brain. Hippocampus 17, 618-626. doi: 10.1002/hipo.20298

Strokes, M., Thompson, R., Cusack, R., and Duncan, J. (2009). Top-down activation of shape-specific population codes in visual cortex during mental imagery. J. Neurosci. 29, 1565-1572. doi: 10.1523/JNEUROSCI.4657-08.2009

Tadel, F., Baillet, S., Mosher, J. C., Pantazis, D., and Leahy, R. M. (2011). Brainstorm, a userfriendly application for MEG-EEG analysis. Comput. Intell. Neurosci. 2011, 879716. doi: 10.1155/2011/879716

Tadel, F., Bock, E., Niso, G., Mosher, J. C., Cousineau, M., Pantazis, D., et al. (2019). MEG/EEG group analysis with Brainstorm. Front.n Neurosci. 13:76. doi: 10.3389/fnins.2019.00076

Valko, Y., Lewis, R. F., Priesol, A. J., and Merfeld, D. M. (2012). Vestibular labyrinth contributions to human whole-body motion discrimination. J. Neurosci. 32, 13537-13542. doi: 10.1523/jneurosci.2157- 12.2012

Vass, L. K., and Epstein, R. A. (2017). Common neural representations for visually guided reorientation and spatial imagery. Cereb. Cortex 27, 1457-1471. doi: $10.1093 /$ cercor/bhv343

Ventre-Dominey, J., and Vallee, B. (2007). Vestibular integration in human cerebral cortex contributes to spatial remapping. Neuropsychologia 45, 435-439. doi: 10.1016/j.neuropsychologia.2006.06.031

Vianni, S., Tanskanen, T., Seppa, M., Uutela, K., and Hari, R. (2001). Coinciding early activation of the human primary visual cortex and anteromedial cuneus. Proc. Natl. Acad. Sci. U.S.A. 98, 2776-2780. doi: 10.1073/pnas.041600898

Wager, T. D., and Smith, E. E. (2003). Neuroimaging studies of working memory. Cogn. Affect. Behav. Neurosci. 3, 255-274. doi: 10.3758/CABN.3.4.255

Wolbers, T., Hegarty, M., Büchel, C., and Loomis, J. M. (2008). Spatial updating: how the brain keeps track of changing object locations during observer motion. Nat. Neurosci. 11, 1223-1230. doi: 10.1038/nn.2189

Woldorff, M., Hansen, J. C., and Hillyard, S. A. (1987). Evidence for effects of selective attention in the mid-latency range of the human auditory event-related potential. Electroencephalogr. Clin. Neurophysiology Supplement 40, 146-154.

Zaehle, T., Jordan, K., Wüstenberg, T., Baudewig, J., Dechent, P., and Mast, F. W. (2007). The neural basis of the egocentric and allocentric spatial frame of reference. Brain Res. 1137, 92-103. doi: 10.1016/j.brainres.2006.12.044

Conflict of Interest: The authors declare that the research was conducted in the absence of any commercial or financial relationships that could be construed as a potential conflict of interest.

Publisher's Note: All claims expressed in this article are solely those of the authors and do not necessarily represent those of their affiliated organizations, or those of the publisher, the editors and the reviewers. Any product that may be evaluated in this article, or claim that may be made by its manufacturer, is not guaranteed or endorsed by the publisher.

Copyright $\odot 2022$ Blouin, Pialasse, Mouchnino and Simoneau. This is an open-access article distributed under the terms of the Creative Commons Attribution License (CC BY). The use, distribution or reproduction in other forums is permitted, provided the original author(s) and the copyright owner(s) are credited and that the original publication in this journal is cited, in accordance with accepted academic practice. No use, distribution or reproduction is permitted which does not comply with these terms. 